\title{
Komparasi Algoritma Denoising Dan Binarization Dengan Adaptive Thresholding Dan Morfologi Untuk Menigkatkan Kualitas Keterbacaan Citra Naskah Lontar (Takepan) Sasak
}

\author{
LM Samsu1*, Muhammad Saiful2, Hariman Bahtiar ${ }^{3}$ \\ 1,2,3Program Studi Sistem Informasi, Universitas Hamzanwadi \\ *Imsamsu311275@gmail.com
}

\begin{abstract}
Abstrak
Salah satu warisan budaya benda yang ada di Nusa Tenggara Barat khusunya Lombok adalah takepan (naskah lontar kuno). Takepan ditulis pada lembaran daun Lontar (daun Duntan dalam bahasa Sasak) dikenal dengan aksara jejawan (turunan dari bahasa jawa kuno).Menurut dalam penelitianya pada segmentasi citra aksara jawa, nilai adaptive thresholding di peroleh berdasarkan variasi itensitas tiap lokal windows.[1] Proses penentuan nilai thresholdingnya bekerja pada blok-blok dalam citra. Citra yang memiliki variasi kontras dan pencahayaan tinggi sangat sulit diklasifikasi sebagai background atau foreground karena terdapat banyak piksel, sebaiknya menggunakan Local Adaptive Thresholding. Dari penelitian yang sudah di lakukan dapat simpulkan bahwa adaptive thresholding dan morfologi dengan pendekatan dilasi sangat membantu memaksimalkan keterbacaan citra dengan nilai Peak Signal to Noise Ratio (PSNR) tertinggi mencapai $34.107 \mathrm{~dB}$.
\end{abstract}

Kata Kunci: denoising, binarization, adaptive thresholding, morfologi, image processing

\begin{abstract}
One of the cultural heritages in West Nusa Tenggara, especially Lombok, is takepan (ancient lontar manuscripts). Takepan written on Lontar leaf sheets (Duntan leaf in Sasak language) is known as the jejawan script (derived from ancient Javanese language). According to in his research on image segmentation of Javanese script, the adaptive thresholding value was obtained based on the variation in the sensitivity of each local windows. [1] The process of determining the thresholding value works on blocks in the image. Images that have high contrast and high lighting variations are very difficult to classify as background or foreground because there are a lot of pixels, you should use Local Adaptive Thresholding. From the research that has been done, it can be concluded that adaptive thresholding and morphology with dilation approach really help maximize image readability with the highest Peak Signal to Noise Ratio (PSNR) value reaching 34,107 dB.
\end{abstract}

Keywords: denoising, binarization, adaptive thresholding, morphology, image processing

\section{Pendahuluan.}

Indonesia memiliki budaya warisan kekayaan dari nenek moyang yang memiliki nilai sejarah. warisan budaya ini dibagi menjadi 2, warisan benda dan tak benda. Hasil kebudayaan yang dapat dilihat dan dirasakan dengan tangan dan mata seperti artefak, aksitektur kuno dan lain lain disebut warisan budaya benda. Sebaliknya warisan budaya tak benda yaitu tidak dapat dilihat maupun dirasakan dengan tangan. Contohnya adalah tradisi lisan dan ekspresinya, seni pertunjukan, ritual perayaan dan festival, keterampilan serta pengetahuan.

Salah satu warisan budaya benda yang ada di Nusa Tenggara Barat khususnya Lombok adalah takepan (naskah lontar kuno). Takepan ditulis pada lembaran daun Lontar dikenal dengan aksara jejawan (turunan dari bahasa jawa kuno). 
Seiring perjalan waktu, takepan mengalami penurunan kualitas (terdegradasi) disebabkan oleh jamur, rayap serta goresan yang mengenai tulisan sehingga ada noda pada background.[2] Ada beberapa penelitian yang sudah dilakukan dan dikembangkan untuk citra terdegradasi menggunakan algoritma thresholding.[3] Thresholding merupakan salah satu teknik segmentasi citra yang populer dalam pemisahan antara background dan foreground, karena kecepatan waktu serta simple untuk diimplementasikan.[4]

\section{Tinjauan Pustaka}

\subsection{Penelitian Terkait}

Penelitian yang dilakukan bisa dimanfaatkan dalam dunia medis menggunakan adative tresholding untuk mendapatkan citra panoramik gigi. selain itu, metode tresholding digunakan juga di dalam segmentasi citra digital guna menentukan jenis tulang daun.[5],[6] Sedangkan untuk citra dokumen terdegradasi menggunakan adaptive thresholding untuk mendapatkan nilai biner. [7]

Menurut dalam penelitiannya pada segmentasi citra aksara jawa, nilai adaptive thresholding di peroleh berdasarkan variasi itensitas tiap lokal windows.[1] Proses penentuan nilai thresholdingnya bekerja pada blok-blok dalam citra. Citra yang memiliki variasi kontras dan pencahayaan tinggi sangat sulit diklasifikasi sebagai background atau foreground sebab terdapat banyak piksel, sebaiknya menggunakan Local Adaptive Thresholding. Oleh karena itu, pada penelitian ini menggunakan adaptive tresholding dan morfologi untuk perbaikan citra. Sehingga dapat meningkatkan kualitas serta kemampuan membaca pada citra takepan.

Penelitian yang dilakukan (L M Samsu dan Aswian Editri Sutriandi, 2014) teknik denoising dan binarization dapat membantu meningkatkan keterbacaan naskah takepan sasak, kemudian kombinasi teknik manakah yang sesuai dengan setiap permasalahan yang dijumpai terkait kondisi fisik naskah.

Penelitian yang dilakukan (L M Samsu dan Imam Fathurrahman, 2019) Teknik Adaptive Thresholding dan Morfologi dengan pendekatan dilasi sangat membantu memaksimalkan keterbacaan citra dengan nilai Peak Signal to Noise Ratio (PSNR) tertinggi mencapai 34.107 $\mathrm{Db}$

\subsection{Landasan Teori}

1. Filosofis Naskah Lontar (Takepan) Sasak.

Kata lontar sendiri berasal dari bahasa Jawa yaitu rountal. Kata roun berarti daun dan tal berarti pohon Siwalan, yaitu sejenis pohon palem. Bila di Jawa disebut dengan rountal, maka di Lombok sendiri disebut dengan lontar. Pemilihan kata lontar sendiri bukan dengan sembarangan memilih kata tanpa makna. Secara filosofis, dikatakan lontar karena ada unsur melontar. Lontar yang berlembarlembar kemudian dijepit atau ditakep dengan kayu. Makna dari proses penakepan ini, yaitu setelah isi ditangkap kemudian isi lontar yang berlembar-lembar itu dipahami, dihayati, dan 
disimpan dalam hati dan pikiran. Selain itu, dalam takepan naskah lontar terdapat benang yang digunakan untuk mengikat naskah lontar sehingga menjadi sebuah takepan. Benang yang digunakan untuk mengikat takepan ini dipilih benang yang halus. Secara filosofis, benang halus ini bermakna sifat pengikat hubungan batin yang halus yang diisi oleh sifat Allah yaitu alrahman dan al-rahim. selain itu, benang yang halus juga sebagai simbolisasi tali silaturrahim yang halus antara orang yang satu dengan lainnya.

\section{Denoising}

Algoritma dalam upaya menghilangkan noise dari citra dengan jenis filter tertentu dimana tiaptiap pendekatan memiliki asumsi, keunggulan dan keterbatasan masing-masing. Teknik-teknik tersebut dapat dibagi dalam dua kategori yakni teknik filtering pada spatial domain dan teknik filtering pada transform domain. [1]

\section{Spatial Domain}

Spatial filter memanfaatkan intensitas nilai pixel di sekitar suatu koordinat untuk menentukan nilai pada pada koordinat tersebut. Teknik pada kategori ini kemudian dibagi lagi menjadi teknik non-linier dan linier. Tenik non linier yang umum digunakan adalah teknik median dan weighted median, sedangkan teknik linier yang populer dalam spatial domain adalah teknik mean dan wiener. Kelemahan teknik spatial secara umum adalah teknik ini mampu mengurangi noise namun memberikan efek blur kepada citra.

\section{Transporm Domain}

Teknik filter pada transform domain memanfaatkan teknik transformasi data dari satu domain ke domain lainnya untuk kemudahan pemrosesan. Data kemudian dikembalikan ke domain asal setelah pemrosesan dilakukan. Teknik filter pada transform domain dapat diklasifikasikan atas teknik data adaptive transform dan non-data adaptif transform. Teknik yang lebih populer digunakan adalah teknik nondata adaptive yang kemudian dibagi lagi atas teknik pada domain wavelet dan teknik pada domain spatial frequency.

\section{Binarization}

Binarization atau dikenal dengan juga dengan threshold selection merujuk kepada teknik konversi citra dalam format grayscale menjadi citra dalam format biner (hitam-putih). [2] Teknik ini dapat dilakukan secara global maupun lokal. Metode global menggunakan suatu nilai pembatas (threshold) tunggal yang berlaku untuk keseluruhan pixel pada citra. Sedangkan metode lokal menggunakan nilai pembatas yang berubah-ubah (adaptif) sesuai dengan informasi di area sekitar pixel.Teknik yang umum digunakan untuk global thresholding antara lain metode Otsu, Sedangkan teknik yang digunakan untuk local thresholding antara lain menggunakan metode Niblack dan Sauvola. [2] 


\section{Metode Penelitian}

\subsection{Tahapan Penelitian}

Pada penelitian ini dilakukan beberapa tahapan untuk meningkatkan kualitas keterbacaan citra takepan. Tahapan yang dilakukan sebagai berikut :

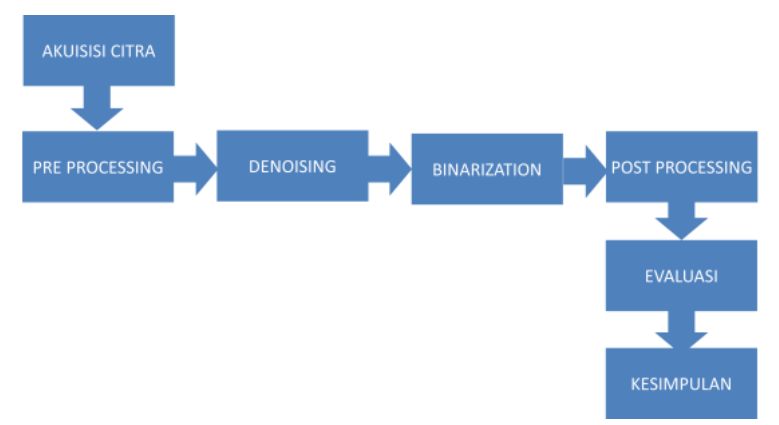

Gambar 1. Tahapan metode yang diusulkan

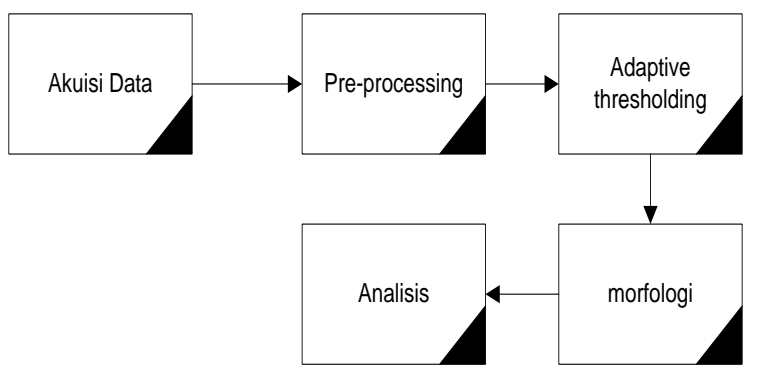

Gambar 2. Tahapan metode yang diusulkan

\section{a. Akuisi Data}

Ini merupakan tahapan awal untuk memperoleh data dari data analog menjadi data digital yaitu citra takepan. Dalam prosesnya menggunakan scanner dengan format JPG dan diperoleh 1,5 s.d 2 Megapixel dari masing masing sample, sehingga untuk penelitian ini terdapat 5 citra takepan.

\section{b. Pre processing}

Pada tahapan pre processing, proses croping perlu dilakukan pada citra takepan yang ada. Dengan cara menghilangkan bagian yang tidak di perlukan, hingga diperoleh data sample yang sesuai dan digunakan untuk tahap selanjutnya.

\section{c. Denoising}

Algoritma dalam upaya menghilangkan noise dari citra dengan jenis filter tertentu dimana tiaptiap pendekatan memiliki asumsi, keunggulan dan keterbatasan masing-masing. Teknik-teknik tersebut dapat dibagi dalam dua kategori yakni teknik filtering pada spatial domain dan teknik filtering pada transform domain. [1]

\section{d. Spatial Domain}

Spatial filter memanfaatkan intensitas nilai pixel di sekitar suatu koordinat untuk menentukan nilai pada pada koordinat tersebut. Teknik pada kategori ini kemudian dibagi lagi menjadi teknik non-linier dan linier. Tenik non linier yang umum digunakan adalah teknik median dan weighted median, sedangkan teknik linier yang populer dalam spatial domain adalah teknik mean dan wiener. Kelemahan teknik spatial secara umum adalah teknik ini mampu mengurangi noise namun memberikan efek blur kepada citra.

\section{e. Transporm Domain}

Teknik filter pada transform domain memanfaatkan teknik transformasi data dari satu domain ke domain lainnya untuk kemudahan pemrosesan. Data kemudian dikembalikan ke domain asal setelah pemrosesan dilakukan. Teknik filter pada transform domain dapat diklasifikasikan atas teknik data adaptive transform dan non-data adaptif transform. Teknik 
yang lebih populer digunakan adalah teknik nondata adaptive yang kemudian dibagi lagi atas teknik pada domain wavelet dan teknik pada domain spatial frequency.

\section{f. Binarization}

Binarization atau dikenal dengan juga dengan threshold selection merujuk kepada teknik konversi citra dalam format grayscale menjadi citra dalam format biner (hitam-putih). [2] Teknik ini dapat dilakukan secara global maupun lokal. Metode global menggunakan suatu nilai pembatas (threshold) tunggal yang berlaku untuk keseluruhan pixel pada citra. Sedangkan metode lokal menggunakan nilai pembatas yang berubah-ubah (adaptif) sesuai dengan informasi di area sekitar pixel.Teknik yang umum digunakan untuk global thresholding antara lain metode Otsu, Sedangkan teknik yang digunakan untuk local thresholding antara lain menggunakan metode Niblack dan Sauvola. [2]

\section{g. Adaptive Tresholding}

Metode Adaptive Thresholding yaitu menghitung nilai ambang lokal yang mempunyai dua nilai dalam tingkat keabuan. Metode ini merupakan proses mengubah background menjadi putih dan foreground menjadi hitam yaitu di sebut biner. Secara umum dengan rumus sebagai berikut.

$$
G(x, y)=\left\{\begin{array}{l}
1 \text { if } f(x, y) \geq T \\
0 \text { if } f(x, y)<T
\end{array}\right.
$$

- $G(x, y)$ menyatakan citra biner dari grayscale $f(x, y)$

- T menyatakan nilai ambang (threshold).
- sehingga untuk rumus adaptive tresholding:

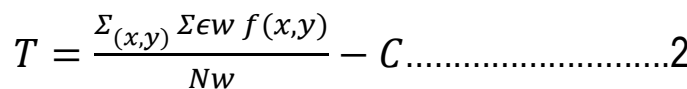

- W merupakan blok yang diproses,

- NW merupakan jumlah piksel pada setiap blok W,

- C merupakan konstanta yang dapat ditentukan secara bebas.

Bila $C=0$, berarti nilai ambang sama dengan nilai rata-rata setiap piksel pada blok bersangkutan.

\section{Morfologi}

setelah mengubah citra takepan menjadi biner tahapan selanjutnya adalah dilasi, merupakan salah satu operasi morfologi yang berfungsi untuk pelebaran atau penambahan pixel pada batasan dalam suatu citra. Dalam prosesnya merubah titik latar (0) yang bertetangga dengan titik objek (1) menjadi titik objek (1).

\section{Analisis}

Untuk mengetahui kualitas secara kuantitas dalam metode yang diusulkan, peneliti menggunakan Peak Signal-to-Noise Ratio (PSNR). Semakin tinggi nilai PSNR artinya hasil thresholding semakin baik. Pada PSNR, dua buah citra dikatakan memiliki tingkat kemiripan yang rendah jika nilai PSNR di bawah $30 \mathrm{~dB}$.

\subsection{Lokasi Penelitian}

Naskah lontar (takepan) sasak yang tersebar di Kota Mataram, Kabupaten Lombok Barat, Lombok Tengah dan Lombok Timur Propinsi Nusa Tenggara Barat. 


\section{Hasil dan Pembahasan}

Terdapat 5 citra takepan sasak yang di gunakan sebagai dataset dengan nilai kostanta $(C)=0,04$ pada adaptive thresholding dapat dilihat pada tabel 1.

Tabel 1. Hasil metode yang di usulkan

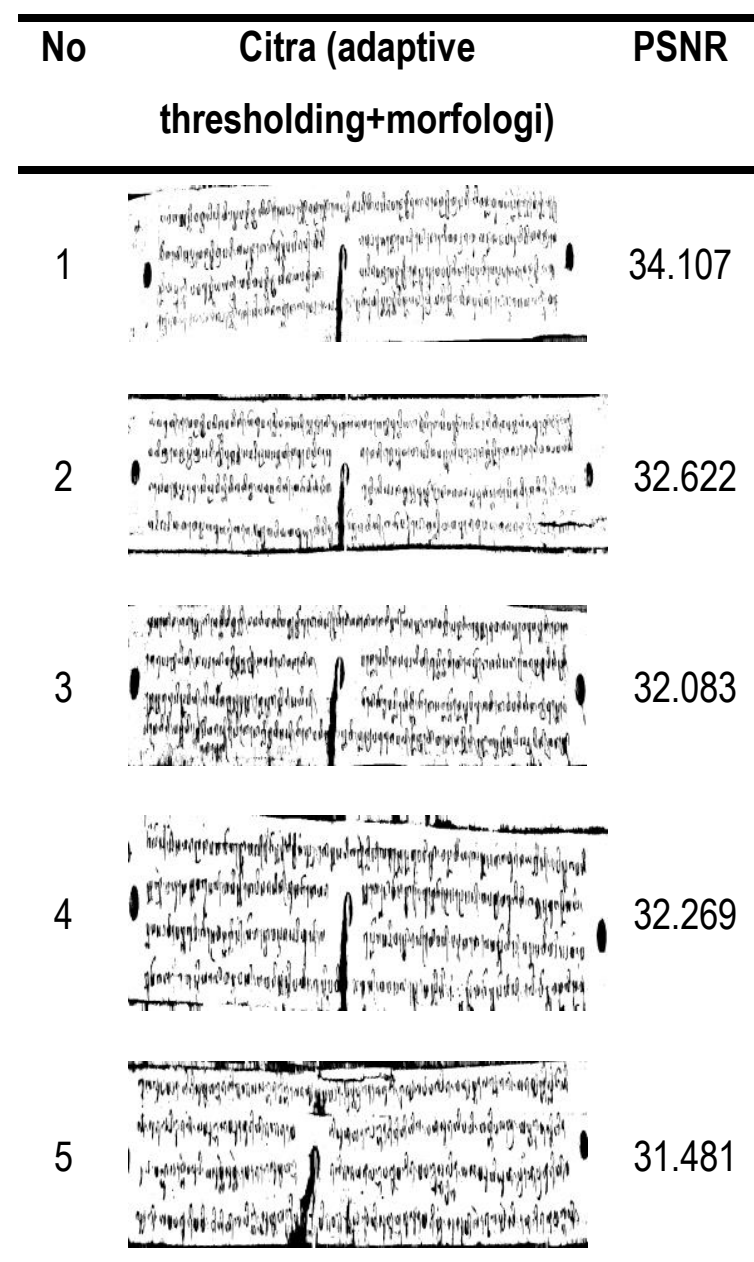

Diperoleh data tabel 1 menggunakan adaptive thresholding dan morfologi Peak Signal-to-Noise Ratio (PSNR) setiap citra takepan sasak memperoleh nilai di atas $30 \mathrm{~dB}$. Untuk citra no. 1 memiliki nilai PSNR 34.107 lebih tinggi dibandingkan 4 citra lainya.

\section{Kesimpulan}

Dari penelitian yang sudah di lakukan dapat simpulkan bahwa Adaptive Thresholding dan Morfologi dengan pendekatan dilasi sangat membantu memaksimalkan keterbacaan citra dengan nilai Peak Signal to Noise Ratio (PSNR) tertinggi mencapai $34.107 \mathrm{~dB}$ dibandingkan dengan teknik Denoising dan Binarization. Pada penelitian selanjutnya dapat di kembangkan menggunakan ekstraksi ciri sehingga dapat mengenali karakter huruf pada takepan.

\section{Daftar Pustaka}

[1] T. Arifianto, "Segmentasi Aksara Pada Tulisan Aksara Jawa Menggunakan Adaptive Threshold," STIKI Inform. J., vol. 7, no. May, pp. 01-015, 2017.

[2] L. M. Samsu dan A. E. Sutriandi, "Eksplorasi Kombinasi Algoritma Denoising Dan Binarization Untuk Pengolahan Citra Digital Naskah Lontar (Takepan) Sasak," 2016, pp. 28-29.

[3] Y. Pai, Y. Chang, and S. R. A, "Adaptive thresholding algorithm: Efficient computation technique based on intelligent block detection for degraded document images," Pattern Recognit., vol. 43, no. 9, pp. 3177-3187, 2010, doi: 10.1016/j.patcog.2010.03.014.

[4] R. C. Gonzalez and R. E. Woods, Digital Image Processing Third Edition, 3rd ed. New Jersey: Pearson Education,inc., 2008.

[5] R. W. Nur Nafi'iyah, "Perbandingan Otsu Dan Iterative Adaptive Thresholding Dalam," J. IIm. Teknol. dan Inf. ASIA, vol. 11, no. 1, pp. 21-28, 2017.

[6] E. Maria, Y. P. Arinda, and P. Nobel, "Segmentasi Citra Digital Bentuk Daun Pada Tanaman Di Politani Samarinda Menggunakan Metode Thresholding," JURTI, vol. 2, no. 1, pp. 37-46, 2018.

[7] A. Z. Arifin, A. Y. Wijaya, and L. Cahyani, "Algoritma Thresholding Adaptif Berdasarkan Deteksi Blok Terhadap Citra 
Infotek : Jurnal Informatika dan Teknologi

Vol. 3 No. 2, Juli 2020, hal. 204-210

Dokumen Terdegradasi," pp. 1-6, 2011

[8] L M Samsu dan Imam Fathurrahman, 2019)

Teknik Adaptive Thresholding dan Morfologi dengan pendekatan dilasi sangat membantu memaksimalkan keterbacaan citra dengan nilai Peak Signal to Noise Ratio (PSNR) tertinggi mencapai $34.107 \mathrm{~dB}$, "Proceeding, HICTE-2019) 